(2) Open Access Full Text Article

\title{
Assessing the response of morphea and limited scleroderma to tranilast: a small prospective study comparing topical corticosteroids to a combination of topical corticosteroids and tranilast
}

This article was published in the following Dove Press journal: Clinical, Cosmetic and Investigational Dermatology

\section{Rowland Noakes}

Queensland Institute of Dermatology, Greenslopes Private Hospital Campus, Greenslopes, QLD, Australia
Correspondence: Rowland Noakes Queensland Institute of Dermatology, Greenslopes Private Hospital Campus, Entrance, Denman St, Greenslopes QLD $4 \mid 20$, Australia

Email ky_n_urenine@hotmail.com
Background: Scleroderma is traditionally managed with immunomodulatory agents such as methotrexate, mycophenolate mofetil and corticosteroids. There are anecdotal reports for, and theoretical reasons why, the anti-fibrotic agent tranilast may provide an additional treatment modality.

Objective: The objective of the current study was to demonstrate if the addition of topical tranilast to an established regime resulted in an improvement in the Localized Scleroderma Assessment Tool (LoSCAT) and modified Rodnan score.

Patients and methods: A small double-blinded randomized prospective study of 11 pairs of treatment sites in four patients; three with morphea and one with limited scleroderma was performed. All patients continued with their prescribed treatment and applied $0.1 \%$ betamethasone valerate in PCCA PracaSil ${ }^{\mathrm{TM}}$ (B) to the control site with $0.1 \%$ betamethasone valerate and $1 \%$ tranilast $(\mathrm{B} / \mathrm{T})$ to the comparator site over a period of 3 months. Photographs and monthly LoSCAT scores were performed on the morphea patients and a modified Rodnan score on the limited scleroderma patient. Statistical analysis was via sign test.

Results: The mean baseline LoScat score at the B treated sites was 6.6 which improved to 4.3 $(p=0.16)$. The mean baseline LoScat score at the $\mathrm{B} / \mathrm{T}$ treated sites was 5.75 which improved to 2.8 following treatment. $(p=0.04)$

Limitations: This was a small single center study. The ideal concentration of tranilast is unknown. As all patients continued with standard management the expected response may be less than would have been anticipated in a single agent trial.

Conclusion: The role of tranilast in the management in scleroderma warrants further investigation in larger trials.

Keywords: morphea, limited scleroderma, tranilast, kynurenine

\section{Introduction}

Scleroderma is a disorder characterized by cutaneous, and in systemic variants, systemic sclerosis. Systemic variants display respiratory, esophageal and renal involvement or esophageal involvement only. The latter is known as limited scleroderma. Previously the acronym CREST (Calcinosis, Raynaud's, Esophageal dysmotility, Telangiectasia) was used to describe this syndrome. 
The term morphea is used to describe scleroderma where only the skin is involved. Recognized variants include frontoparietal, plaque, linear, generalized, subcutaneous, keloidal and a pan sclerotic variant. Atrophic variants known as Atrophoderma of Pasini and Pierini, Parry-Romberg syndrome, and linear atrophoderma of Moulin are also recognized. Eosinophilic fasciitis is included in the morphea spectrum by many authorities. ${ }^{1}$

The etiology of this class of disorders is poorly defined but they are classified as autoimmune diseases due to their known association with other autoimmune diseases ${ }^{2}$ and the presence of auto-antibodies. ${ }^{3}$

Endothelial injury is proposed to be the initiating event. ${ }^{4}$ The initial cellular infiltrate is monocytic, ${ }^{5}$ a class of leucocytes known to express the kynurenine pathway (KP). ${ }^{6}$ Subsequently lymphocytes are present in the inflammatory infiltrate, dominated by $\mathrm{TH} 1$ and $\mathrm{TH} 17$ cells ${ }^{7}$ which express a profibrotic cytokine profile. ${ }^{8}$ The cytokine profile later shifts to $\mathrm{TH} 2^{7}$ presumably under the influence of the KP.

The KP is the metabolic pathway by which L-tryptophan is converted to nicotinamide. In addition, it serves an important immune regulatory role by controlling the availability of the essential amino acid L-tryptophan within the microenvironment. ${ }^{9}$ As the least common of the essential amino acids, L-tryptophan availability is a rate limiting factor for cell division and thus $\mathrm{T}$ cell proliferation. $\mathrm{T}$ lymphocytes monitor L tryptophan availability via a GCN2 kinase, ${ }^{10}$ activation of which promotes $\mathrm{T}$ cell apoptosis. ${ }^{11}$ The rate limiting enzyme is indoleamine 2,3 dioxygenase (IDO) ${ }^{12}$ which is induced by interferon gamma ${ }^{13}$ thus providing a negative feedback loop on immune stimulation and vascular endothelial growth factor (VEGF) ${ }^{14}$ which is expressed in response to endothelial injury. ${ }^{15}$ The relationship to $\mathrm{T}$ cell apoptosis is complex however with kynurenine metabolites selectively promoting the apoptosis of TH1 cells ${ }^{16}$ with preservation of the TH2 cells thus promoting a $\mathrm{TH} 2$ skewed cytokine environment. In addition, several KP metabolites are natural ligands of the aryl hydrocarbon receptor ${ }^{17-19}$ binding to which releases pp60 ${ }^{\text {src }}$ which plays a role on fibroblast activation. ${ }^{20}$

Expression of the principal fibrotic cytokine transforming growth factor beta (TGF beta) is altered in scleroderma. ${ }^{21}$ Pathogenic antibodies generated in the TH2 skewed environment include those directed against fibrillin $1^{22,23}$ which inhibit the sequestration of TGF beta by the extracellular matrix, matrix- metalloproteinase-1 (MMP-1) antibodies which inhibit collagenase activity ${ }^{24}$ and anti-endothelial antibodies ${ }^{25}$ which perpetuate endothelial damage. Finally, TGF beta is known to promote
IDO expression ${ }^{26}$ this generating further KP metabolites providing a positive feedback loop.

Tranilast (N-[3,4-dimethoxycinnamoyl]-anthranilic acid) is an agent approved in Japan and South Korea for the management of allergic and fibrotic disorders. It is a derivative of the kynurenine metabolite 3 -hydroxyanthranilic acid. Its reported actions include the inhibition of chemical mediator release, ${ }^{27}$ the inhibition of fibroblast proliferation and collagen production ${ }^{28}$ and modulation of the KP. ${ }^{29-31}$

PCCA PracaSil ${ }^{\mathrm{TM}}$ (Professional Compounding Chemists of America, Houston, TX, USA) is a compounded anhydrous silicone base containing Pracaxi oil. Pracaxi oil is derived from the seeds of the Pentaclethra macroloba tree. It contains oleic, linoleic, and behenic fatty acids, and oleic acid has been reported to enhance the absorption of topical tranilast in rats. ${ }^{32}$

\section{Patients and methods Ethical approval and registration}

Ethics approval was obtained from the Greenslopes Private Hospital Ethics Committee (Newdegate Street Greenslopes, QLD, Australia) and the trial was registered with the Australian New Zealand Clinical Trials Registry (ANZCTR) as: Assessing the response of limited scleroderma to manipulation of the KP. A prospective study comparing topical corticosteroids vs topical corticosteroids/tranilast- Universal Trial Number (UTN) U1111-1177-3064.

Written informed consent was obtained from all participants.

\section{Study population}

A total of 11 pairs of treatment sites in four patients were identified. Exclusion criteria included pregnancy, age $<18$ years, documented allergy to ingredients and significant hepatic, renal, or hematological disease.

Ages ranged from 21 to 90 and diagnoses included plaque, linear and generalized morphea, and limited scleroderma.

All patients continued with their routine therapy. This varied form sole therapy in plaque disease and limited scleroderma to methotrexate in generalized morphea and methotrexate and hydroxychloroquine in linear morphea. Patient characteristics and treatments are summarized in Table 1. All systemic agents had been introduced prior to enrollment in the trial and doses remained unchanged during the trial.

\section{Study design}

Betamethasone valerate $0.1 \%$ in pracisal (B) was used as a control with betamethasone valerate $0.1 \%$ and tranilast $1 \%$ 
Table I Patient characteristics

\begin{tabular}{|c|c|c|}
\hline $\begin{array}{l}\text { Characteristics } \\
\text { (sex, age) }\end{array}$ & Diagnosis & Adjuvant therapy \\
\hline Female, 21 years & Plaque morphea & Nil \\
\hline Male, 90 years & Limited scleroderma & Nil \\
\hline Female, 25 years & Linear morphea & $\begin{array}{l}\text { Methotrexate } 20 \mathrm{mg} \\
\text { weekly, hydroxychloroquine } \\
400 \mathrm{mg} \text { daily }\end{array}$ \\
\hline Male, 77 years & $\begin{array}{l}\text { Generalized } \\
\text { morphea }\end{array}$ & Methotrexate $10 \mathrm{mg}$ weekly \\
\hline
\end{tabular}

in pracisal $(\mathrm{B} / \mathrm{T})$ at the contralateral treatment site. Both agents were prepared by a registered compounding pharmacy (Wickham House Compounding Pharmacy, Brisbane, QLD, Australia).

A total of 11 pairs of treatment sites were identified. Randomization was done via the MS Excel random number function. Number one was used to assign $B / T$ application to the proximal/right treatment site with $\mathrm{B}$ to the comparator site and number two to assign B application to the proximal/ right treatment site with $\mathrm{B} / \mathrm{T}$ to the comparator site. The list was provided to the study coordinator who liaised with the patients. The investigators were blinded to the randomization protocol. Each treatment site was palm sized. Thirty grams per month was used at each treatment site.

The study population was provided with written instructions including diagrams on where and how to apply the trial agents and reviewed accordingly. All treatment sites were spatially separated by areas of clinically noninvolved skin except for the patient illustrated in Figure 1A where the two plaques were immediately adjacent but considered morphologically sufficiently distinct to assess the responses to treatment.

Assessment was via Localized Scleroderma Assessment Tool (LoScat). Assessments were performed by the same observer and photographs of the involved sites were taken. At the completion of the study LoScat scores and images were collated, and scores confirmed. A representative series of images are shown in Figure 1A-E. The LoScat scores were performed at treatment sites only. This included all the involved areas in all subjects apart from one plaque in the subject with generalized morphea which was not suitable for inclusion.

\section{Safety}

No adverse events were reported.

\section{Results}

Overall the mean baseline LoScat score at the B treated sites was 6.6 which improved to 4.3 following treatment $(p=0.16)$. The mean baseline LoScat score at the $\mathrm{B} / \mathrm{T}$ treated sites was
5.75 which improved to 2.8 following treatment $(p=0.04)$. This was derived from the addition of the Localized Scleroderma Activity Skin Index (mLoSSI) and the Localized Scleroderma Skin Damage Index (LoSDI).

Considering each component individually the mean of the mLoSSI at the B treated sites improved from 4.1 to 2.5. The LoSDI at the B treated sites deteriorated marginally from 2.5 to 2.75 . At the $\mathrm{B} / \mathrm{T}$ sites the mean mLoSSI improved from 3.9 to 1.4 and the LoSDI improved from 1.9 to 1.4.

In the limited scleroderma patient, the mean modified Rodnan score improved from a baseline of 2 at both the B and $B / T$ sites to a mean of 1.3 at the $B$ treated sites and 1 at the $\mathrm{B} / \mathrm{T}$ treated sites.

The Physician Global Assessment of Activity (PGA-A) improved from 52 at baseline to 25 at the $\mathrm{B}$ sites $(p=0.03)$ and 51 to 17.5 at the $\mathrm{B} / \mathrm{T}$ sites $(p=0.01)$

The Physician Global Assessment of Damage (PGA-D) improved from 32.5 at baseline to 27 at the $\mathrm{B}$ sites ( $p=0.31$ ), and 35 to 21 at the $\mathrm{B} / \mathrm{T}$ treated sites $(p=0.45)$.

The correlation was stronger between the LoScat and PGA-A scores compared to PGA-D as has been previously reported. ${ }^{33}$

Interestingly no disease progression was noted at the $\mathrm{B} / \mathrm{T}$ treatment sites whereas disease progression was noted at two of the B treatment sites. One is shown in Figure 1C and D. The before and after images in Figure 1C reveal progression at the B treatment site over a 3-month period whereas no progression is seen at the adjacent $\mathrm{B} / \mathrm{T}$ treatment site.

\section{Discussion}

These results are consistent with previous case reports which support a role for tranilast in the management of scleroderma, primarily as an adjuvant to established therapies. Interestingly only combined therapy with systemic agents where indicated, and a combination of topical betamethasone and tranilast demonstrated statistically significant improvement at a 3-month interval indicating that variants of this disease with a poorer prognosis, that is variants near joints, frontoparietal variants, and generalized variants require aggressive management early in the course of the disease if complications are to be prevented. The limited improvement in the PGA-D score at all sites is consistent with the observation that once tissue damage is established treatment is unlikely to reverse it in the short term.

The rarity of morphea makes the establishment of evidence-based guidelines difficult. The best evidence exists for methotrexate in combination with systemic steroids and UVA1 therapy. ${ }^{34}$ 
A
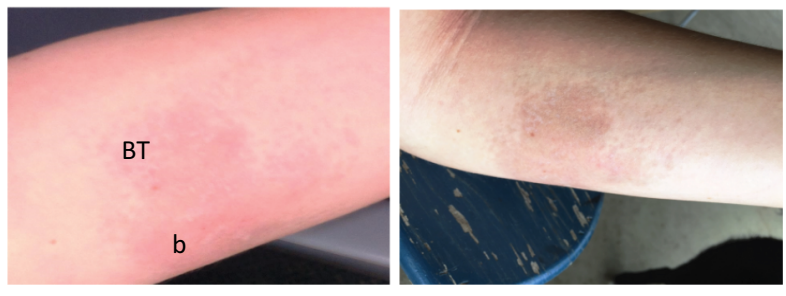

B
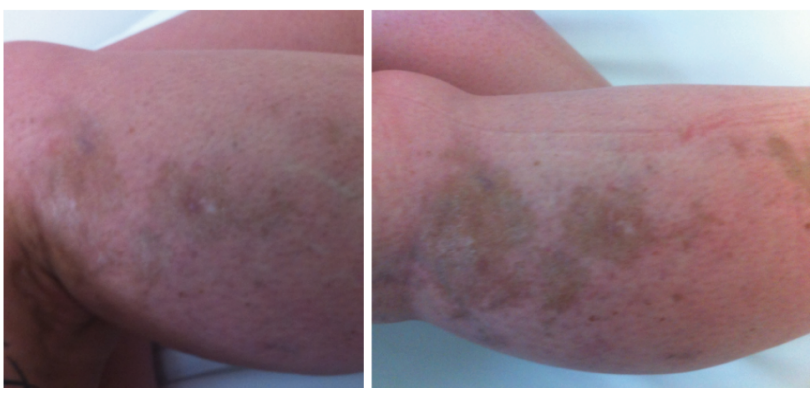

C
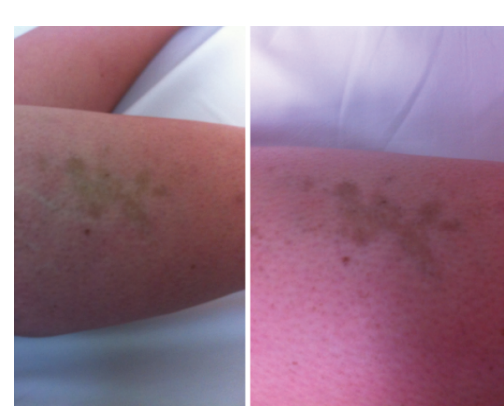

D

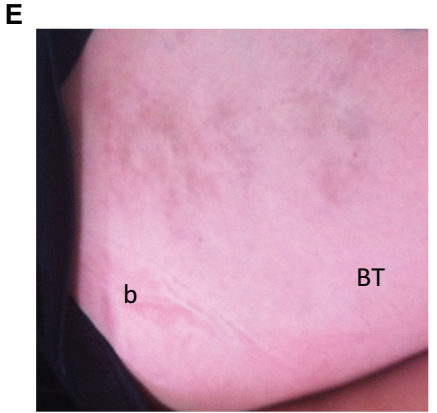

Figure I (A). Plaque morphea. Pre- (left side) and immediate posttreatment images. Betamethasone treatment site is labeled b and betamethasone/tranilast site is labeled BT. Persisting erythema indicating ongoing disease activity is noted at the $b$ site whereas the disease has resolved with post inflammatory hyperpigmentation at the BT site. (B) Linear morphea. Pre- and immediate posttreatment images at the $b$ treatment site demonstrating disease progression has occurred over 3 months. (C) Linear morphea. Pre- and immediate posttreatment images at the Figure IB adjacent BT treatment site demonstrating no disease progression. (D) Limited scleroderma. Immediate posttreatment image. There is persisting induration at the b site compared to the BT treatment site. (E) Linear morphea post treatment image. The BT has improved more quickly than the $b$ site at the completion of the 3-month trial.

Abbreviations: b, betamethasone; BT, betamethasone/tranilast;

There are anecdotal reports of success in treating morphea with tranilast ${ }^{35}$ and its known properties ${ }^{27-31}$ indicate it is an agent whose potential needs further exploration. Up regulation of the KP has been demonstrated in morphea ${ }^{36}$ and there are sound theoretical reasons, as outlined above, why targeting this pathway may provide a more targeted therapy.

\section{Limitations}

This study, by necessity, has several limitations. First, the disease incidence is 2.7 per $100,000^{37}$ which limits to the size of the study population. Second, the fact tranilast was added to established therapies reduced the measured effect. Third, the bioavailability of topical tranilast is not well 
established however studies in rats indicate that topical delivery, especially with agents to enhance absorption, may be a more effective means of delivery than oral administration. ${ }^{32}$

Interestingly no disease progression was detected at the $\mathrm{B} / \mathrm{T}$ treated sites whereas it was noted at two B treated sites. One example is shown in Figure $1 \mathrm{C}$ and $\mathrm{D}$ where progression is noted over a 3-month period at the B treated site (Figure 1C) whereas no progression is noted at the $\mathrm{B} / \mathrm{T}$ site (Figure 1D).

As tranilast's major mechanism of action involves the TGF beta pathway ${ }^{38}$ and the principle pharmacological effects in morphea is anti-fibrotic the LoSCAT scoring system, which includes inflammatory markers may not be the ideal means of assessing the response to tranilast treatment. In this regard changes in the modified Rodnan used in the patient with limited scleroderma may more directly measure the response to tranilast therapy.

The lack of disease progression at treated sites was an interesting finding suggesting the drug may be targeting the disorder more specifically than established therapies. Further evaluation of the role of the KP in cutaneous sclerosing disorders is warranted as targeted therapies against this pathway may offer more specific treatment.

\section{Disclosure}

The author has no conflicts of interest in this work.

\section{Reference}

1. Peterson, L.S., Nelson, A.M., and Su, W.P. Classification of morphea (localized scleroderma). Mayo Clin Proc. 1995;70:1068-1076

2. Leitenberger JJ, Cayce RL, Haley RW, Adams-Huet B, Bergstresser PR, Jacobe HT. Distinct autoimmune syndromes in morphea: a review of 245 adult and pediatric cases. Arch Dermatol. 2009;145(5): $545-550$.

3. Fett N, Werth VP. Update on morphea: part I. Epidemiology, clinical presentation, and pathogenesis. J Am Acad Dermatol. 2011;64(2):217-228.

4. Sartori-Valinotti JC, Tollefson MM, Reed AM. Updates on morphea: role of vascular injury and advances in treatment. Autoimmune Diseases. 2013; article ID 467808.

5. Kräling BM, Maul GG, Jimenez SA. Mononuclear cellular infiltrates in clinically involved skin from patients with systemic sclerosis of recent onset predominantly consist of monocytes/macrophages. Pathobiology. 1995; 63(1):48-56.

6. Jones SP, Franco NF, Varney B, et al. Expression of the kynurenine pathway in human peripheral blood mononuclear cells: implications for inflammatory and neurodegenerative disease. PLoS one. 2015;10(6): 0131389.

7. Kurzinski K, Torok KS. Cytokine profiles in localized scleroderma and relationship to clinical features. Cytokine. 2011;55(2):157-164.

8. Yang X, Yang J, Xing X, Wan L, Li M. Increased frequency of Th17 cells in systemic sclerosis is related to disease activity and collagen overproduction. Arthritis Res Ther. 2014;16(1):1.

9. Munn DH, Zhou M, Attwood JT, et al. Prevention of allogeneic fetal rejection by tryptophan catabolism. Science. 1998;281(5380):1191-1193.

10. Fallarino F, Grohmann U, You S, et al. Tryptophan catabolism generates autoimmune-preventive regulatory T cells. Transpl Immunol. 2006;17(1):58-60
11. Lee GK, Park HJ, Macleod M, Chandler P, Munn DH, Mellor AL. Tryptophan deprivation sensitizes activated $\mathrm{T}$ cells to apoptosis prior to cell division. Immunology. 2002;107(4):452-460.

12. Platten M, Wick W, Van den Eynde BJ. Tryptophan catabolism in cancer: beyond IDO and tryptophan depletion. Cancer Res. 2012;72(21): 5435-5440.

13. Widner B, Werner ER, Schennach H, Wachter H, Fuchs D. Simultaneous measurement of serum tryptophan and kynurenine by HPLC. Clin Chem. 1997;43(12):2424-2426.

14. Marti LC, Pavon L, Severino P, Sibov T, Guilhen D, Moreira-Filho CA. Vascular endothelial growth factor-A enhances indoleamine 2, 3-dioxygenase expression by dendritic cells and subsequently impacts lymphocyte proliferation. Mem Inst Oswaldo Cruz. 2014;109(1):70-79.

15. Dziankowska-Bartkowiak B, Zebrowska A, Wagrowska-Danielewicz M, Kobos J, Waszczykowska E. [Systemic sclerosis and scleroderma circumscripta--disturbances of selected serum parameters which are responsible for vascular changes and $\mathrm{CD} 34$ expression in involved skin]. Przegl Lek. 2008;66(12):1040-1045. Polish.

16. Fallarino F, Grohmann U, Vacca C, et al. T cell apoptosis by tryptophan catabolism. Cell Death Differ. 2002;9(10):1069-1077.

17. Mezrich JD, Fechner JH, Zhang X, Johnson BP, Burlingham WJ, Bradfield CA. An interaction between kynurenine and the aryl hydrocarbon receptor can generate regulatory T cells. J Immunol. 2010;185(6): 3190-3198.

18. DiNatale BC, Murray IA, Schroeder JC, et al. Kynurenic acid is a potent endogenous aryl hydrocarbon receptor ligand that synergistically induces interleukin- 6 in the presence of inflammatory signaling. Toxicol Sci. 2010;115(1):89-97.

19. Lowe MM, Mold JE, Kanwar B, et al. Identification of cinnabarinic acid as a novel endogenous Aryl hydrocarbon receptor ligand that drives IL-22 production. PLoS One. 2014;9(2):e87877

20. Skhirtladze C, Distler O, Dees C, et al. Src kinases in systemic sclerosis: central roles in fibroblast activation and in skin fibrosis. Arthritis Rheum. 2008;58(5):1475-1484.

21. Denton CP, Abraham DJ. Transforming growth factor- $\beta$ and connective tissue growth factor: key cytokines in scleroderma pathogenesis. Curr Opin Rheumatol. 2001;13(6):505-511.

22. Arnett FC, Tan FK, Uziel Y, Laxer RM, Krafchik BR, Antohi S, Bona C. Autoantibodies to the extracellular matrix microfibrillar protein, fibrillin 1, in patients with localized scleroderma. Arthritis Rheum. 1999;42(12):2656-2659.

23. Tan FK, Arnett FC, Antohi S, et al. Autoantibodies to the extracellular matrix microfibrillar protein, fibrillin-1, in patients with scleroderma and other connective tissue diseases. J Immunol. 1999;163(2):1066-1072.

24. Tomimura S, Ogawa F, Iwata Y, et al. Autoantibodies against matrix metalloproteinase-1 in patients with localized scleroderma. J Dermatol Sci. 2008;52(1):47-54.

25. Mihai C, Tervaert JW. Anti-endothelial cell antibodies in systemic sclerosis. Ann Rheum Dis. 2010;69(2):319-324.

26. Belladonna ML, Volpi C, Bianchi R, et al. Cutting edge: autocrine TGF- $\beta$ sustains default tolerogenesis by IDO-competent dendritic cells. J Immunol. 2008;181(8):5194-5198.

27. Suzawa H, Kikuchi S, Arai N, Koda A. The mechanism involved in the inhibitory action of tranilast on collagen biosynthesis of keloid fibroblasts. Jpn J Pharmacol. 1992;60(2):91-96.

28. Yamada H, Tajima S, Nishikawa T, Murad S, Pinnell SR. Tranilast, a selective inhibitor of collagen synthesis in human skin fibroblasts. $J$ Biochem. 1994;116(4):892-897.

29. Noakes RR. Effects of tranilast on the urinary excretion of kynurenic and quinolinic acid under conditions of $\mathrm{L}$ tryptophan loading. Int $J$ Tryptophan Res. 2013;6:67-71.

30. Chen Y, Guillemin GJ. Kynurenine pathway metabolites in humans: disease and healthy states. International journal of tryptophan research: Int J Tryptophan Res. 2009;2:1-19.

31. Lovelace MD, Varney B, Sundaram G, et al. Current evidence for a role of the kynurenine pathway of tryptophan metabolism in multiple sclerosis. Front Immunol. 2016;7:246. 
32. Murakami T, Yoshioka M, Yumoto R, et al. Topical delivery of keloid therapeutic drug, tranilast, by combined use of oleic acid and propylene glycol as a penetration enhancer: evaluation by skin microdialysis in rats. J Pharm Pharmacol. 1998;50(1):49-54.

33. Kelsey CE, Torok KS. The localized scleroderma cutaneous assessment tool: responsiveness to change in a pediatric clinical population. $\mathrm{J} \mathrm{Am}$ Acad Dermatol. 2013;69(2):214-220.

34. Fett N, Werth VP. Update on morphea: part II. Outcome measures and treatment. J Am Acad Dermatol. 2011;64(2):231-242.
35. Taniguchi S, Yorifuji T, Hamada T. Treatment of linear localized scleroderma with the anti-allergic drug, tranilast. Clin Exp Dermatol. 1994;19(5):391-393.

36. Noakes R, Mellick N. Immunohistochemical studies of the kynurenine pathway in morphea. Int J Tryptophan Res. 2013;6:97-102.

37. Peterson LS, Nelson AM, Su WP, Mason T, O'Fallon WM, Gabriel SE. The epidemiology of morphea (localized scleroderma) in Olmsted County 1960-1993. J Rheumatol. 1997;24(1):73-80.

38. Darakhshan S, Pour AB. Tranilast: a review of its therapeutic applications. Pharmacol Res. 2015;91:15-28.

\section{Publish your work in this journal}

Clinical, Cosmetic and Investigational Dermatology is an international, peer-reviewed, open access, online journal that focuses on the latest clinical and experimental research in all aspects of skin disease and cosmetic interventions. This journal is included on PubMed. The manuscript management system is completely online and includes a very quick and fair peer-review system, which is all easy to use. Visit http://www.dovepress.com/testimonials.php to read real quotes from published authors 